\title{
Influence of Molybdenum and Tungsten on the Formation of Zirconium Oxide Coatings on a Steel Base
}

\author{
Amangul Bold ${ }^{1,2, *(\mathbb{D}}$, Larissa Sassykova ${ }^{2} \mathbb{D}$, Lidiya Fogel ${ }^{1}$, Tigran Vagramyan ${ }^{3}$ and Aleksey Abrashov $^{3} \mathbb{D}$ \\ 1 D.V. Sokolsky Institute of Fuel, Catalysis and Electrochemistry, JSC, 142, Kunaev Str., Almaty 050010, \\ Kazakhstan; fogel.lidiya@mail.ru \\ 2 Faculty of Chemistry and Chemical Technology, Al-Farabi Kazakh National University, 71, Al-Farabi Ave., \\ Almaty 050040, Kazakhstan; larissa.rav@mail.ru \\ 3 Department of Innovative Materials and Corrosion Protection, D.I. Mendeleev University of Chemical \\ Technology of Russia, 9, Miusskaya Sq., 125047 Moscow, Russia; vagramyan@muctr.ru (T.V.); \\ aabrashov@muctr.ru (A.A.) \\ * Correspondence: b.amangul@inbox.ru; Tel.: +7-707-874-96-84
}

Citation: Bold, A.; Sassykova, L.;

Fogel, L.; Vagramyan, T.; Abrashov, A Influence of Molybdenum and Tungsten on the Formation of Zirconium Oxide Coatings on a Steel Base. Coatings 2021, 11, 42. https:// doi.org/10.3390/coatings11010042

Received: 11 December 2020 Accepted: 28 December 2020 Published: 2 January 2021

Publisher's Note: MDPI stays neutral with regard to jurisdictional clai$\mathrm{ms}$ in published maps and institutional affiliations.

Copyright: $(2021$ by the authors. Licensee MDPI, Basel, Switzerland. This article is an open access article distributed under the terms and conditions of the Creative Commons Attribution (CC BY) license (https:// creativecommons.org/licenses/by/ $4.0 /)$.

\begin{abstract}
In this paper, we have developed conditions for the deposition of zirconium oxide coatings from solutions containing hexafluorozirconic acid as well as tungsten and molybdenum salts on a steel base. Based on electrochemical studies, it was shown that the addition of tungsten and molybdenum salts to the solution to deposit zirconium oxide coatings led to the inhibition of the anodic process of iron ionization. It was shown that the optimal conditions for the deposition of oxide-zirconium coatings on the surface of steel samples from a solution of $0.2 \mathrm{~g} / \mathrm{L} \mathrm{Zr}(\mathrm{IV})+0.15 \mathrm{~g} / \mathrm{L}$ $\mathrm{W}(\mathrm{VI})+0.1 \mathrm{~g} / \mathrm{L} \mathrm{Mo}(\mathrm{VI})$ were a deposition temperature of $30^{\circ} \mathrm{C}$ and time of $10 \mathrm{~min}$. The thickness of the oxide-zirconium coatings formed under these conditions was $64.72 \mathrm{~nm}$, the adhesion value was $3.17 \mathrm{MPa} / \mathrm{s}$, and the corrosion resistance was $26 \mathrm{~s}$ according to Akimov's drop method. The depth of corrosive penetration, determined in the salt fog chamber, did not exceed $2 \mathrm{~mm}$ after $240 \mathrm{~h}$ of testing, meeting the requirements for adhesive layers under the paintwork.
\end{abstract}

Keywords: zirconium oxide coatings; hexafluorozirconic acid; molybdenum; tungsten; cyclic voltammetry; protective ability; surface structure; thickness; adhesion

\section{Introduction}

One of the most common methods for protecting metal structures from corrosion is the deposition of anti-corrosion protective coatings. The priorities for improving anti-corrosion coating deposition processes include increasing the protective and other functional properties. In the process of deposition of anti-corrosion coatings, it is necessary to further reduce the environmental hazard that these processes involve, as well as the concentration of the solutions used and the temperature and time for deposition of protective coatings. Recently, ceramic coatings have been gaining in popularity since they have high thermal and electrical resistance and are also more resistant to oxidation, corrosion [1-8], erosion, and wear in high-temperature environments. Diamond nanoparticles, as well as those of other chemical compounds used for the deposition of hard coatings $(\mathrm{SiC}, \mathrm{ZrO}$, and $\mathrm{Al}_{2} \mathrm{O}_{3}$ ), are commercially available, with a particle size in the range of 4-300 nm. Some of the most promising ceramic coatings are nanostructured zirconium oxide layers containing zirconium dioxide $\left(\mathrm{ZrO}_{2}\right)[9,10]$. Zirconium dioxide deposited from a solution provides the formation of chemical bonds of the produced film with both the metal base and with the subsequent paint and varnish coating. According to the literature [11,12], solutions for the formation of such coatings, in addition to hexafluorozirconic acid, should contain heavy metal ions such as nickel, copper, chromium, cobalt, and molybdenum, etc. Heavy metal ions form active centers that contribute to the deposition of zirconium oxide produced as a result of hydrolysis of hexafluorozirconic acid at $\mathrm{pH} 4.5$ and 5.5 and room temperature [13-15]. In this work, we consider the combined effect of Mo (VI) and W (VI) ions on 
the formation of a zirconium oxide coating on the surface of steel samples. Since corrosion processes can be represented through a course of cathodic and anodic processes on a metal surface, the cyclic voltammetry method was used to study the corrosion resistance of the formed anticorrosive coatings. The method of cyclic voltammetry makes it possible to obtain independent information on the processes occurring on steel samples during the deposition of oxide-zirconium coatings, and at the same time to assess the degree of their corrosion resistance $[7,16]$. The corrosion resistance of the formed oxide-zirconium coatings was determined by the ionization current of the iron electrode at a certain potential. The proposed electrochemical method for assessing the anticorrosion resistance of coatings on steel samples can be used to establish the qualitative and quantitative composition of phosphating solutions and control the anticorrosive activity of the formed oxide-zirconium coatings.

\section{Materials and Methods}

\subsection{Material}

The reagents sodium sulfate $\left(\mathrm{Na}_{2} \mathrm{SO}_{4}\right)$, hexafluorozirconic acid $\left(\mathrm{H}_{2} \mathrm{ZrF}_{6}\right)$ solution 50 wt.\% in water, $\left(\mathrm{NH}_{4}\right)_{6} \mathrm{Mo}_{7} \mathrm{O}_{24}$, and $\mathrm{C}\left(\mathrm{NH}_{4}\right)_{10} \mathrm{~W}_{12} \mathrm{O}_{41} \cdot n \mathrm{H}_{2} \mathrm{O}$ of "Pure" and "Chemically Pure" grades and distilled water were used.

\subsection{Sample Preparation}

Plates of cold-rolled steel (grade Art. 08ps) were used as samples. The steel composition is shown in Table 1.

Table 1. Chemical composition of Art. 08ps.

\begin{tabular}{cc}
\hline Chemical Element & Content, $\%$ \\
\hline Iron (Fe) & 60.8 \\
\hline Chromium (Cr) & $17-19$ \\
\hline Nickel (Ni) & $9-11$ \\
\hline Manganese (Mn) & $\leq 2$ \\
\hline Silicon (Si) & $\leq 0.8$ \\
\hline Copper (Cu) & $\leq 0.3$ \\
\hline Carbon (C) & $\leq 0.08$ \\
\hline Phosphorus (P) & $\leq 0.035$ \\
\hline Sulfur (S) & $\leq 0.02$ \\
\hline
\end{tabular}

Pretreatment of metal plates was carried out by degreasing in an aqueous alkaline detergent composition with a concentration of $15-20 \mathrm{~g} / \mathrm{L}$ at a temperature of $60-65{ }^{\circ} \mathrm{C}$ for 2-10 min. Then, the surface of metal plates was cleaned with abrasive material, followed by washing with distilled water.

The deposition of the oxide-zirconium coating was carried out at room temperature with stirring on a rotating unit RDE710 with a rotation speed of $500 \mathrm{rpm}$. Using a pH meter I-130, (Tokyo, Japan) the allowable $\mathrm{pH}$ range of coating formation was established. After coating, the plates were dried at a temperature of $130{ }^{\circ} \mathrm{C}$.

\subsection{Methods}

Electrochemical studies included cyclic voltammetry. Cyclic volt-ampere curves were recorded using the potentiostat-galvanostat Gamry Reference 3000 (Warminster, PA, USA), in a sealed three-electrode cell at $25^{\circ} \mathrm{C}$. The working electrode was a steel (grade Art. 08ps) electrode with a visible surface of $0.03 \mathrm{~cm}^{2}$. The counter electrode was a platinum electrode with a surface of $2 \mathrm{~cm}^{2}$. An $\mathrm{Ag} / \mathrm{AgCl}$ electrode, for which the potential was $196 \mathrm{mV}$ relative to the hydrogen electrode, was used as a reference electrode. Cyclic volt-ampere curves 
were recorded in the potential range from -0.3 to $-1.2 \mathrm{~V}$. Before fixing the cyclic currentvoltage curves, the working electrode surface was updated using MIRKA 2000 (JEPPO, Finland). Emery paper was washed with distilled water, then polished on a paper filter (blue tape), and finally washed with distilled water. The used electrolyte was a solution of $0.3 \mathrm{M} \mathrm{Na}_{2} \mathrm{SO}_{4}$ [16].

Corrosion tests of adhesive oxide-zirconium coatings with paint were carried out in an Alcott S450iP salt fog chamber (Staffordshire, UK) in accordance with the international standard ASTM B117 [17].

The thickness of the coatings was determined using a SER 800 spectroscopic ellipsometer (SENTECH Instruments $\mathrm{GmbH}$, Krailling, Germany), which makes it possible to accurately measure the thickness and optical characteristics of both monolayer films and multi-layer film structures during deposition. Measurements were performed in the spectral range of light wavelengths of 240-1000 nm [18].

For an accelerated assessment of the coating's protective ability a rapid method using Akimov's reagent (a solution containing $\mathrm{CuSO}_{4} \cdot 5 \mathrm{H}_{2} \mathrm{O}, \mathrm{NaCl}$, and $\mathrm{HCl}$ ) was used [19]. According to this method, the protective ability of the coating (ASA) is estimated in seconds as the time necessary for a color change from gray to red-brown to take place with a drop of solution in in the control area. In accordance with this method, the corrosion resistance of the oxide-zirconium coating was evaluated using the time (s) taken for a color change from gray to red-brown to take place using a drop of the control solution on the surface of the coating.

The adhesion strength of the coatings was determined by the method of normal separation (the method of fungi) using the digital adhesiometer Posi Test AT (New York, NY, USA). The method is based on measuring the minimum breaking stress required to separate or tear the coating in the direction perpendicular to the substrate surface.

The morphology of the surfaces of the coated specimens was studied using an MPLAPONLEXT 100 lens with the LEXT-OSL 4100 confocal laser microscope (OLYMPUS Corporation, Tokyo, Japan) [20].

\section{Results}

To obtain independent information on the processes occurring on steel samples, during the deposition of ceramic coatings, cyclic voltammetric curves were obtained on an iron electrode in the presence of hexafluorozirconic acid and Mo (VI) and W (VI) metal ions, which affect the protective ability of the formed oxide-zirconium coatings. Cyclic volt-ampere curves were recorded in the potential range from -0.3 to $-1.2 \mathrm{~V}$.

Figure 1 shows the cyclic volt-ampere curves obtained on iron electrode at a constant concentration of $\mathrm{Zr}(\mathrm{IV})$. Electrolyte: $0.3 \mathrm{M} \mathrm{Na}_{2} \mathrm{SO}_{4}+0.2 \mathrm{~g} / \mathrm{L} \mathrm{Zr}$ (IV).

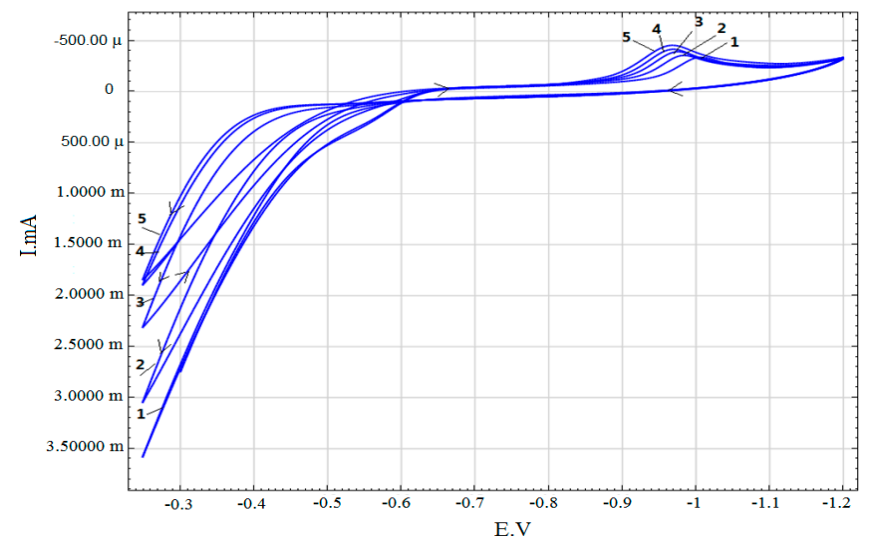

Figure 1. Cyclic volt-ampere curves of an iron electrode (cycles 1-5). 
In Figure 1, the cathode maximum (A) is observed on the cyclic volt-ampere curves at a potential of $-1.0 \mathrm{~V}$.

In Figure 1, a cathode maximum (A) is observed on the cyclic volt-ampere curves at a potential of $-1.0 \mathrm{~V}$ due to the electric reduction of hydroxide compounds formed on the surface of the steel electrode during anodic polarization. In the anodic part of the cyclic volt-ampere curves, with an increase in the number of cycles, a shift of the ionization potential of the iron electrode to the positive region was also observed, indicating an increase in its corrosion resistance.

A study of the effect of Mo (VI) additions on the electrochemical behavior of an iron electrode in a solution of $0.3 \mathrm{M} \mathrm{Na}_{2} \mathrm{SO}_{4}+0.2 \mathrm{~g} / \mathrm{L} \mathrm{Zr}$ (IV) with various concentrations of $\mathrm{Mo}$ (VI) (Figure 2) was carried out.

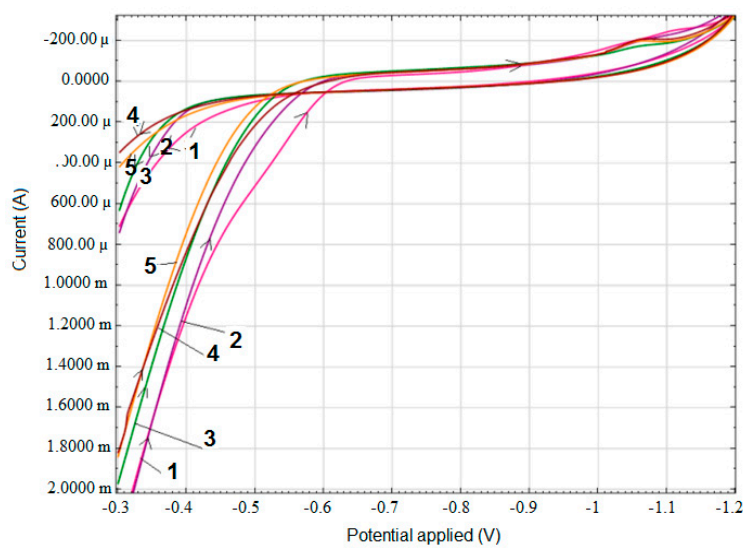

(a)

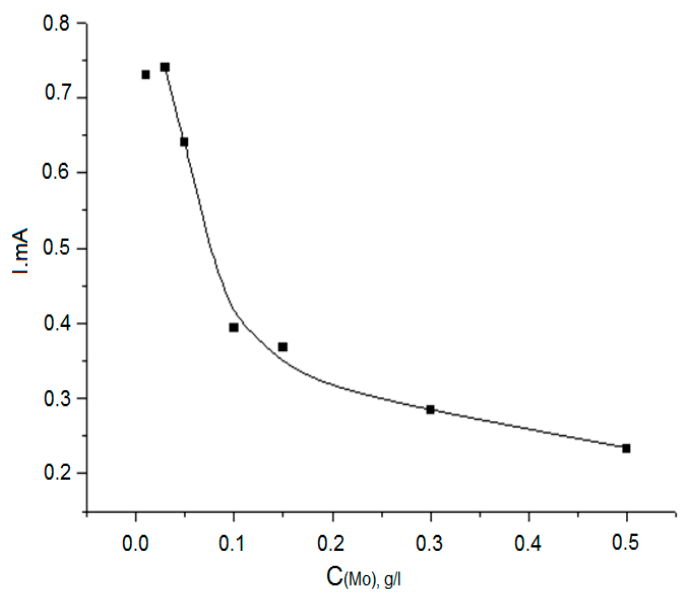

(b)

Figure 2. Volt-ampere curves of an iron electrode (a) and a change in the ionization current of the iron electrode (b) at different concentrations of $\mathrm{Mo}$ (VI). Electrolyte $0.3 \mathrm{M} \mathrm{Na}_{2} \mathrm{SO}_{4}+0.2 \mathrm{~g} / \mathrm{L} \mathrm{Zr}$ (IV) + $\mathrm{Mo}$ (VI) (g/L): $1-0.1 ; 2-0.3 ; 3-0.5 ; 4-1$; 5-1.5.

The concentration of Mo (VI) was changed from 0.1 to $0.15 \mathrm{~g} / \mathrm{L}$.

According to Figure 2a, the addition of small amounts of Mo (VI) from 0.01 to $0.2 \mathrm{~g} / \mathrm{L}$ to the electrolyte composition led to a sharp decrease in the ionization current of the iron electrode (i.e., it contributed to the growth of its corrosion resistance). A further increase in the Mo (VI) content $>0.3 \mathrm{~g} / \mathrm{L}$ led to a smoother decrease in the ionization current of the iron electrode. More clearly, the change in the corrosion resistance of the iron electrode was seen from the dependence of the iron electrode ionization current, determined at a potential of $-0.3 \mathrm{~V}$, on the concentration of Mo (VI) ions in the electrolyte (Figure $2 \mathrm{~b}$ ). Thus, the optimal concentration of $\mathrm{Mo}(\mathrm{VI})$ in solution of $0.3 \mathrm{M} \mathrm{Na}_{2} \mathrm{SO}_{4}+0.2 \mathrm{~g} / \mathrm{L} \mathrm{Zr}$ (IV) for the deposition of an oxide-zirconium coating was chosen to be $0.2 \mathrm{~g} / \mathrm{L}$, at which the ionization current was $0.28 \mathrm{~mA}$.

The effect of the tungsten salt $\mathrm{C}\left(\mathrm{NH}_{4}\right)_{10} \mathrm{~W}_{12} \mathrm{O}_{41} \cdot n \mathrm{H}_{2} \mathrm{O}$ on the electrochemical behavior of the iron electrode was studied (Figure 3). 


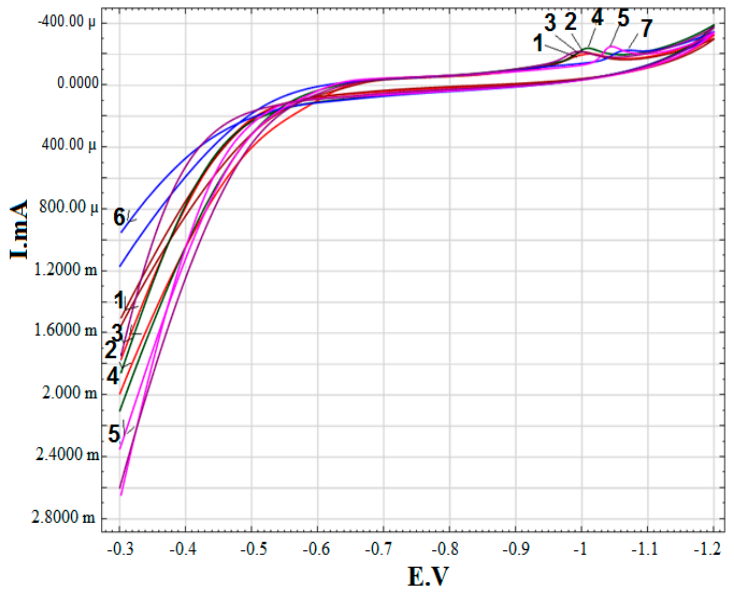

(a)

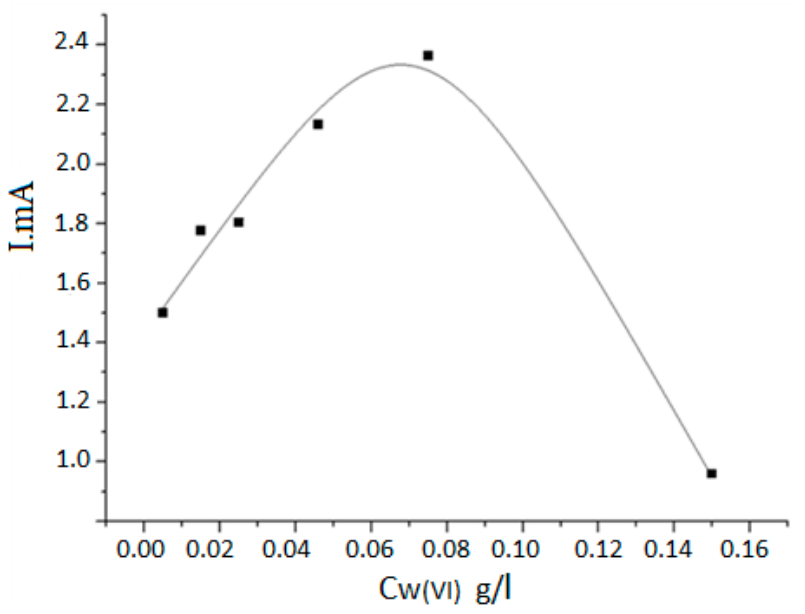

(b)

Figure 3. Volt-ampere curves of an iron electrode (a) and a change in the ionization current of the iron electrode (b) at different concentrations of W(VI). Electrolyte $0.3 \mathrm{M} \mathrm{Na}_{2} \mathrm{SO}_{4}+0.2 \mathrm{~g} / \mathrm{L} \mathrm{Zr}(\mathrm{VI})+\mathrm{W}$ (VI) (g/L): 1-0.005; 2-0.015; 3-0.025; $4-0.05 ; 5-1.5$.

According to Figure $3 a$ at low concentrations of W (VI) from 0.005 to $0.05 \mathrm{~g} / \mathrm{L}$, the value of the maximum current $(\mathrm{A})$ in the cathode part of the volt-ampere curves practically did not change. At a concentration of $\mathrm{W}(\mathrm{VI})>0.05 \mathrm{~g} / \mathrm{L}$, a shift of the cathode maximum towards the negative region and a decrease in its current were observed. In the anodic region, with an increase in the $\mathrm{W}(\mathrm{VI})$ concentration from 0.005 to $0.075 \mathrm{~g} / \mathrm{L}$, a shift of the ionization potential to the cathode region was observed. However, at a higher concentration of $0.15 \mathrm{~g} / \mathrm{L}$, a sharp shift in the ionization potential to the anode region was seen. According to Figure 3b, an increase in the W (VI) concentration from 0.005 to $0.075 \mathrm{~g} / \mathrm{L}$ in the electrolyte of $0.3 \mathrm{M} \mathrm{Na}_{2} \mathrm{SO}_{4}+0.2 \mathrm{~g} / \mathrm{L} \mathrm{Zr}$ (IV) led to an increase in the ionization current of the iron electrode from 1.5 to $2.3 \mathrm{~mA}$. A further increase in the $\mathrm{W}$ (VI) concentration promoted a sharp decrease in the ionization current and an increase in the corrosion resistance of the iron electrode. Thus, at a W (VI) concentration of $0.15 \mathrm{~g} / \mathrm{L}$, the ionization current of the iron electrode was $0.9 \mathrm{~mA}$.

The combined effect of $\mathrm{W}(\mathrm{VI})+\mathrm{Mo}(\mathrm{VI})$ ions on the corrosion resistance of an iron electrode was considered. Figure 4 shows the electrochemical behavior of an iron electrode in an electrolyte containing, in addition to zirconium ions, tungsten and various concentrations of Mo (VI) molybdenum ions. 


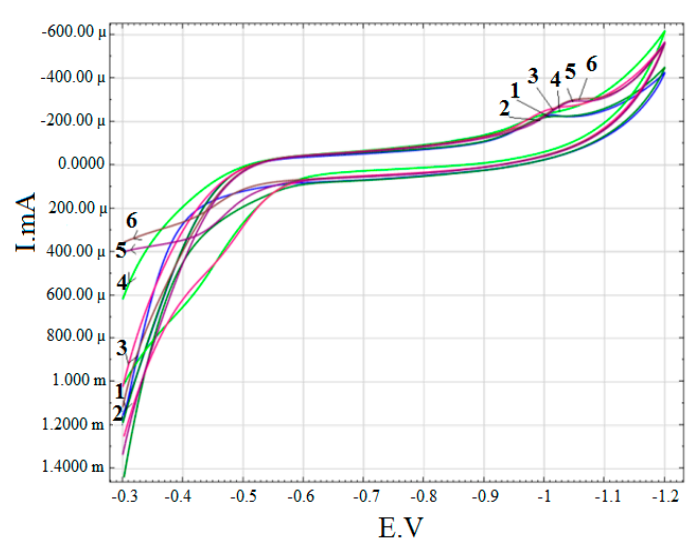

(a)

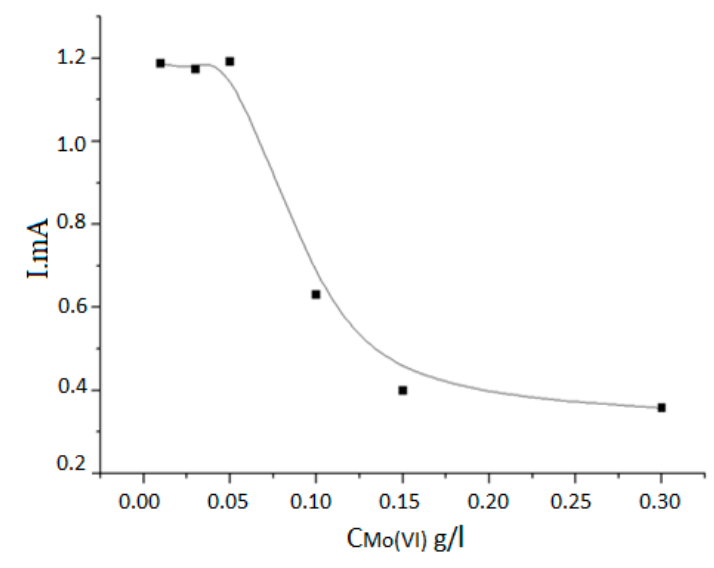

(b)

Figure 4. Volt-ampere curves of an iron electrode in $0.3 \mathrm{M} \mathrm{Na}_{2} \mathrm{SO}_{4}+0.2 \mathrm{~g} / \mathrm{L} \mathrm{Zr}(\mathrm{IV})+0.15 \mathrm{~g} / \mathrm{L} \mathrm{W}$ (VI) (a) and a change in the ionization current of the iron electrode $(\mathbf{b})$ at different concentrations of $\mathrm{Mo}(\mathrm{VI}))(\mathrm{g} / \mathrm{L}): 1-0.1 ; 2-0.3 ; 3-0.5 ; 4-1 ; 5-1.5$.

The concentration of molybdenum in a solution was changed from 0.01 to $0.3 \mathrm{~g} / \mathrm{L}$. According to Figure 4a, the addition of Mo (VI) ions led to the appearance of a small cathode wave at $\mathrm{E}=-1.08 \mathrm{~V}$ and the displacement of iron electrode ionization potential to the anode region, indicating greater difficulty in the ionization process. According to Figure $4 \mathrm{~b}$, an increase in the concentration of molybdenum (VI) from 0.01 to $0.15 \mathrm{~g} / \mathrm{L}$ in solution promoted a sharp reduction of the ionization current from 1.2 to $0.35 \mathrm{~mA}$. A further increase in the tungsten (VI) concentration did not lead to a noticeable change in the ionization current of the iron electrode. Thus, the optimal electrolyte, in which the minimum ionization current of the iron electrode was observed, was the composition: $0.2 \mathrm{~g} / \mathrm{L} \mathrm{Zr}$ (IV) + 0.15 g/L W (VI) + $0.15 \mathrm{~g} / \mathrm{L} \mathrm{Mo} \mathrm{(VI)} \mathrm{shown} \mathrm{in} \mathrm{Table} 2$.

Table 2. Influence of the electrolyte composition on the ionization current of the iron electrode at a potential of $-0.3 \mathrm{~V}$.

\begin{tabular}{cc}
\hline Electrolyte Composition & Ionization Current, $\mathbf{m A}$ \\
\hline $0.3 \mathrm{M} \mathrm{Na}_{2} \mathrm{SO}_{4}+(0.02-1.0 \mathrm{~g} / \mathrm{L}) \mathrm{Zr}(\mathrm{IV})$ & $3.3-1.5$ \\
\hline $0.3 \mathrm{M} \mathrm{Na}_{2} \mathrm{SO}_{4}+0.2 \mathrm{~g} / \mathrm{L} \mathrm{Zr}(\mathrm{IV})+(0.01-0.2 \mathrm{~g} / \mathrm{L}) \mathrm{Mo}(\mathrm{VI})$ & $0.75-0.25$ \\
\hline $0.3 \mathrm{M} \mathrm{Na}_{2} \mathrm{SO}_{4}+0.2 \mathrm{~g} / \mathrm{L} \mathrm{Zr}(\mathrm{IV})+0.15 \mathrm{~g} / \mathrm{L} \mathrm{W}(\mathrm{VI})$ & 0.9 \\
\hline $0.3 \mathrm{M} \mathrm{Na}_{2} \mathrm{SO}_{4}+0.2 \mathrm{~g} / \mathrm{L} \mathrm{Zr}(\mathrm{IV})+0.075 \mathrm{~g} / \mathrm{L} \mathrm{W}(\mathrm{VI})+(0.01-0.3 \mathrm{~g} / \mathrm{L}) \mathrm{Mo}(\mathrm{VI})$ & $1.3-0.4$ \\
\hline $0.3 \mathrm{M} \mathrm{Na}_{2} \mathrm{SO}_{4}+0.2 \mathrm{~g} / \mathrm{L} \mathrm{Zr}(\mathrm{IV})+0.15 \mathrm{~g} / \mathrm{L} \mathrm{W}(\mathrm{VI})+(0.01-0.3 \mathrm{~g} / \mathrm{L}) \mathrm{Mo}(\mathrm{VI})$ & $1.2-0.35$ \\
\hline
\end{tabular}

According to Table 2, the smallest ionization current, and therefore the greatest corrosion resistance of the iron electrode, was observed in the electrolytes:

1. $\quad 0.3 \mathrm{M} \mathrm{Na}_{2} \mathrm{SO}_{4}+0.2 \mathrm{~g} / \mathrm{L} \mathrm{Zr}$ (IV) $+(0.01-0.2 \mathrm{~g} / \mathrm{L}) \mathrm{Mo}(\mathrm{VI})$

2. $\quad 0.3 \mathrm{M} \mathrm{Na}_{2} \mathrm{SO}_{4}+0.2 \mathrm{~g} / \mathrm{L} \mathrm{Zr}(\mathrm{IV})+0.15 \mathrm{~g} / \mathrm{L} \mathrm{W}(\mathrm{VI})+(0.01-0.3 \mathrm{~g} / \mathrm{L}) \mathrm{Mo}(\mathrm{VI})$

The results of the electrochemical study, given in Table 1, were used to select solutions for the deposition of oxide-zirconium coatings on the surface of steel samples with the highest corrosion resistance. Since coatings deposited from solutions containing $\mathrm{Zr}$ (IV) and W (VI) showed the highest corrosion resistance on steel samples with Mo (VI) ions, additional studies were carried out to determine the optimal conditions for the deposition of oxide-zirconium coatings from these solutions.

Figure 5 shows the change in the surface structure of steel samples with deposited oxide-zirconium coatings from a solution of $0.2 \mathrm{~g} / \mathrm{L} \mathrm{Zr}$ (IV) $+0.15 \mathrm{~g} / \mathrm{L} \mathrm{W}$ (VI) with different concentrations of $\mathrm{Mo}(\mathrm{VI})$. The deposition time was $10 \mathrm{~min}$, the deposition temperature was $45^{\circ} \mathrm{C}$, the subsequent drying time was $10 \mathrm{~min}$., and the drying temperature was $-130^{\circ} \mathrm{C}$. 


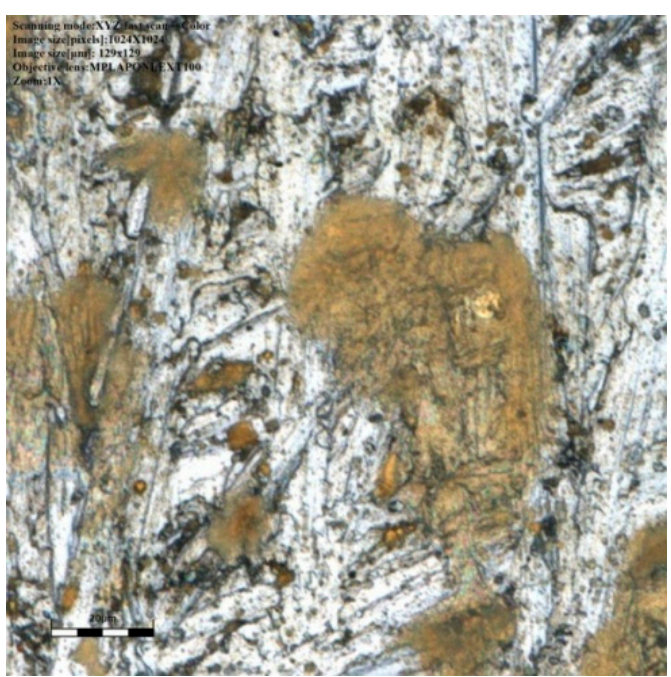

(a)

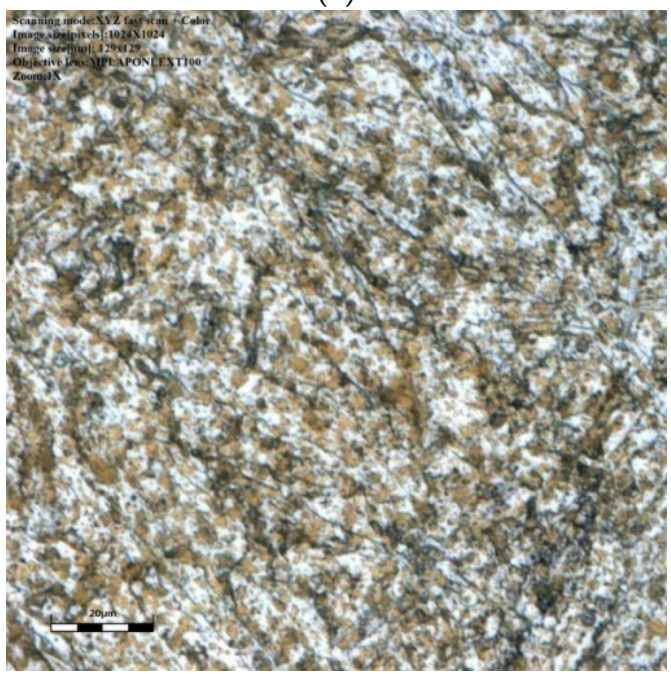

(c)

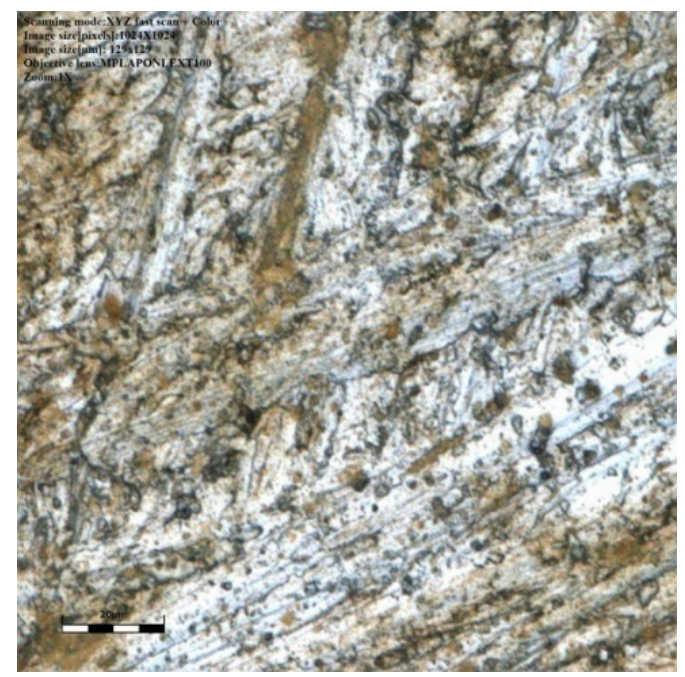

(b)

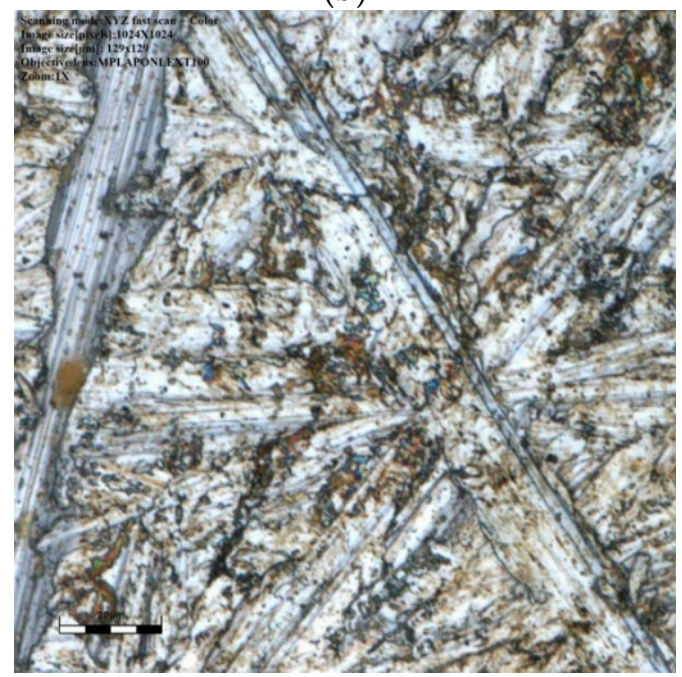

(d)

Figure 5. Micrographs of steel samples with zirconium oxide coatings deposited from the solution: $0.2 \mathrm{~g} / \mathrm{L} \mathrm{Zr}(\mathrm{IV})+0.15 \mathrm{~g} / \mathrm{L} \mathrm{W}$ (VI) (a) and with additions of Mo (VI) of $0.05 \mathrm{~g} / \mathrm{L}$ (b), $0.1 \mathrm{~g} / \mathrm{L}$ (c), and $0.15 \mathrm{~g} / \mathrm{L}$ (d). Size pixels $1024 \times 1024$; size $\mu \mathrm{m} 129 \times 129$.

According to Figure $5 \mathrm{a}$, in the absence of $\mathrm{Mo}$ (VI) ions in the deposition solution: 0.2 $\mathrm{g} / \mathrm{L} \mathrm{Zr} \mathrm{(IV)}+0.15 \mathrm{~g} / \mathrm{L} \mathrm{W}(\mathrm{VI})$, a coating was observed on the surface of the iron sample in certain areas only. When a small concentration of molybdenum $0.05 \mathrm{~g} / \mathrm{L}$ was added to the deposition solution (Figure $5 b$ ), an increase in the surface area with the deposited coating was obtained. However, the coating was also formed only in certain areas. At a molybdenum concentration of $0.1 \mathrm{~g} / \mathrm{L}$, a uniform fine-grained coating was formed (Figure $5 \mathrm{c}$ ) over the entire surface of the iron sample. With an increase in the concentration of $\mathrm{Mo}(\mathrm{VI})$ to $1.5 \mathrm{~g} / \mathrm{L}$, a reduction in the surface with a deposited oxide-zirconium coating and the appearance of microcracks were observed. Microcracks can negatively affect corrosion resistance by creating conductive paths of electrolyte and its penetration through the coating to the base.

The thickness of oxide-zirconium coatings deposited from a solution of $0.2 \mathrm{~g} / \mathrm{L} \mathrm{Zr}$ (IV) $+0.15 \mathrm{~g} / \mathrm{L}$ (VI) with different concentrations of Mo (VI) was investigated (Figure 6). 


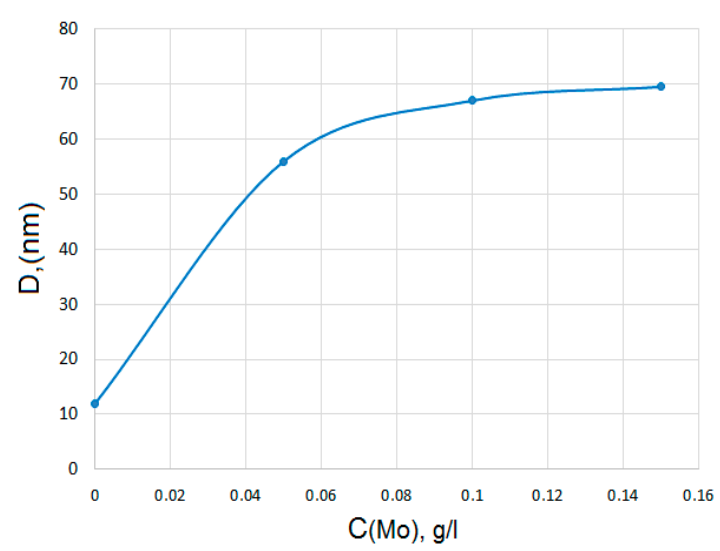

Figure 6. Dependence of the thickness of oxide-zirconium coatings on the concentration of Mo (VI) in the deposition solution.

As seen in Figure 6, with an increase in the concentration of Mo (VI) to $0.05 \mathrm{~g} / \mathrm{L}$ in the deposition solution for oxide-zirconium coatings, a significant increase in the thickness of the formed coatings was observed. Thus, at a Mo (VI) concentration of $0.05 \mathrm{~g} / \mathrm{L}$, the thickness of the coating was $58.01 \mathrm{~nm}$. With a further increase in the concentration of Mo (VI), the thickness of the coatings increased slightly: at $0.1 \mathrm{~g} / \mathrm{L}$, the thickness was $64.72 \mathrm{~nm}$, and at $0.15 \mathrm{~g} / \mathrm{L}$ it was $68.33 \mathrm{~nm}$.

A study of the protective ability of the formed coating using Akimov's method with deposition time was carried out (Figure 7).

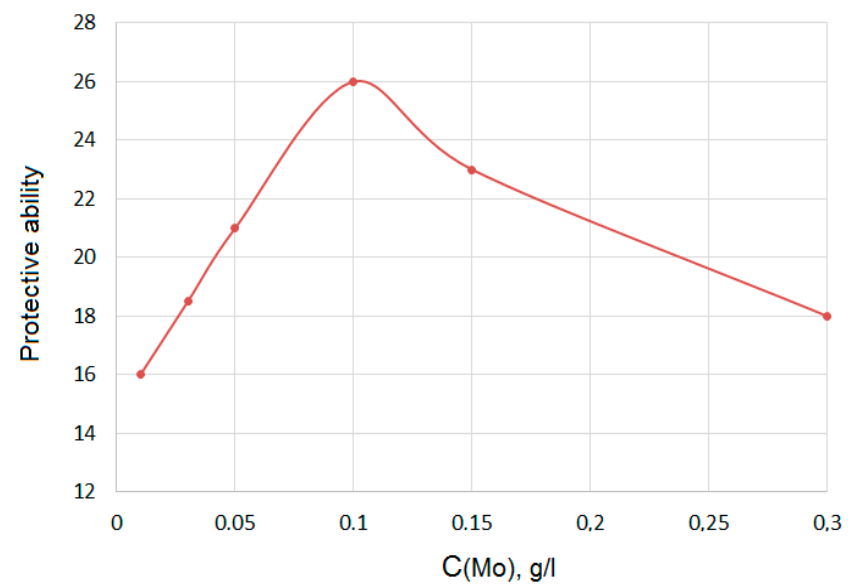

Figure 7. Dependence of the protective ability of oxide-zirconium coatings on the concentration of Mo (VI) in the deposition solution.

According to Figure 7, the protective ability of the oxide-zirconium coating increased significantly with an increase in the concentration of Mo (VI) to $0.1 \mathrm{~g} / \mathrm{L}$. With a further increase in the Mo (VI) concentration in the deposition solution, the protective ability of the coating was reduced. Therefore, the optimal composition of the solution for the deposition of the oxide-zirconium coating was: $0.2 \mathrm{~g} / \mathrm{L} \mathrm{Zr}(\mathrm{IV})+0.15 \mathrm{~g} / \mathrm{L} \mathrm{W}(\mathrm{VI})+0.1 \mathrm{~g} / \mathrm{L} \mathrm{Mo}$ (VI).

An important factor characterizing the possibility of using the obtained coatings is their adhesion strength, which is determined by the strength of the coating adhesion to the steel base. To quantify the bond strength, the normal peel method (fungal method) was used. The dependence of the adhesive strength of the oxide-zirconium coating on the deposition temperature from a solution of $0.2 \mathrm{~g} / \mathrm{L} \mathrm{Zr}(\mathrm{IV})+0.15 \mathrm{~g} / \mathrm{L} \mathrm{W}(\mathrm{VI})+0.1 \mathrm{~g} / \mathrm{L} \mathrm{Mo}$ (VI) is shown in Figure 8. 


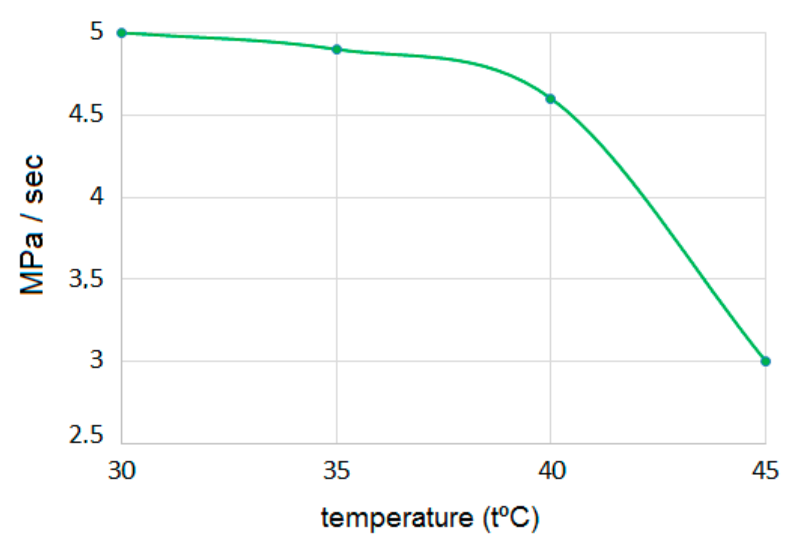

Figure 8. The rate of detachment of the oxide-zirconium coating with deposition temperature.

As seen in Figure 8, at a deposition temperature of $30^{\circ} \mathrm{C}$, the rate of detachment of the coating from the sample surface was $3.17 \mathrm{MPa} / \mathrm{s}$. With a further increase in the deposition temperature, the adhesive strength of the coating was reduced. Consequently, the optimum deposition temperature at which the most durable coatings were formed was $30^{\circ} \mathrm{C}$.

Corrosion tests (ASTM B117 [17].) of steel samples painted with polyester powder paint with an adhesive zirconium-containing coating deposited from a solution of $0.2 \mathrm{~g} / \mathrm{L}$ $\mathrm{Zr}(\mathrm{IV})+0.15 \mathrm{~g} / \mathrm{L} \mathrm{W}(\mathrm{VI})+$ various concentrations of Mo (VI) are shown in Table 3 and Figure 9. The salt spray test was carried out for $240 \mathrm{~h}$.

Table 3. Influence of the concentration of Mo (VI) in the precipitation solution $0.2 \mathrm{~g} / \mathrm{L} \mathrm{Zr}(\mathrm{IV})+$ $0.15 \mathrm{~g} / \mathrm{L} \mathrm{W}$ (VI) on the depth of corrosion penetration determined in the salt fog chamber.

\begin{tabular}{ccccc}
\hline Concentration Mo (VI), g/L & 0 & 0.05 & 0.1 & 0.15 \\
\hline Depth of corrosive penetration, $\mathbf{~ m m}$ & 6 & 2.3 & 1.8 & 3.3 \\
\hline
\end{tabular}

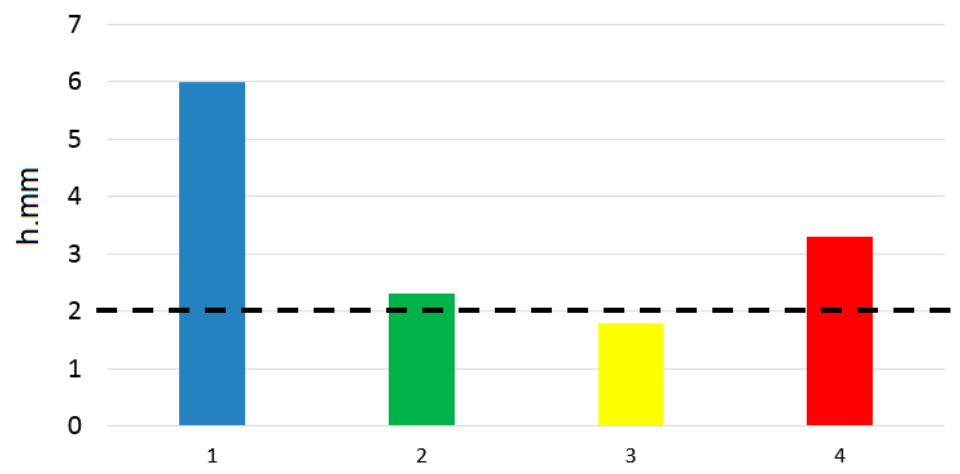

Figure 9. Dependence of the width of the separation of the paintwork from the cuts on concentrations of Mo (VI) g/L: (1) 0; (2) 0.05; (3) 0.1; (4) 0.15 in deposition solution $0.2 \mathrm{~g} / \mathrm{L} \mathrm{Zr} \mathrm{(IV)} \mathrm{+} 0.15 \mathrm{~g} / \mathrm{L} \mathrm{W}$ (VI).

As seen in Figure 9, the depth of corrosion penetration after $240 \mathrm{~h}$ of testing on steel samples with oxide-zirconium coatings deposited from a solution of $0.2 \mathrm{~g} / \mathrm{L} \mathrm{Zr}$ (IV) + $0.15 \mathrm{~g} / \mathrm{L} \mathrm{W}$ (VI) with a concentration of Mo (VI) $0.05 \mathrm{~g} / \mathrm{L}$ was less than $2 \mathrm{~mm}$, exceeding the corrosion resistance of crystalline amorphous phosphate coatings.

\section{Conclusions}

Thus, by studying the electrochemical behavior of individual components and their compositions it was possible to select the optimal composition of the deposition solution in which the formed coatings had the highest corrosion resistance. Based on the studies carried out, it was found that the optimal conditions for the deposition of oxide-zirconium 
coatings on the surface of steel samples from a solution of $0.2 \mathrm{~g} / \mathrm{L} \mathrm{Zr}$ (IV) $+0.15 \mathrm{~g} / \mathrm{L}$ (VI) + $0.1 \mathrm{~g} / \mathrm{L} \mathrm{Mo} \mathrm{(Vi)} \mathrm{are} \mathrm{temperature} 30^{\circ} \mathrm{C}$ and time $10 \mathrm{~min}$.

The thickness of the oxide-zirconium coatings formed under these conditions was $64.72 \mathrm{~nm}$, and the adhesion strength was $3.17 \mathrm{MPa} / \mathrm{s}$. Tests showed that the developed nanocoatings met the requirements for adhesion layers for paint and varnish coatings (LCP) in terms of their protective ability, since the width of corrosion penetration from the notch in these cases did not exceed $2.0 \mathrm{~mm}$ after $240 \mathrm{~h}$ of testing. These coatings are not inferior to phosphate coatings in terms of protective characteristics. It should be noted that zirconium-containing coatings have the smallest thickness and specific gravity in comparison with other coatings. It was revealed that paintwork varnish with a zirconiumcontaining adhesive sublayer had a higher adhesion strength to the base compared to crystalline and amorphous phosphate and chromate coatings $[7,10]$.

Author Contributions: Conceptualization, L.F.; methodology, A.A., L.F., and A.B.; validation, T.V. and L.F.; investigation, A.B. resources, A.B. and L.S.; writing-original draft preparation), L.F. and L.S.; writing-review and editing), L.F., L.S., and A.B. All authors have read and agreed to the published version of the manuscript.

Funding: The reported study was supported by the personal grant of L. R. Sassykova "The best teacher of the university" of Republic of Kazakhstan (2019).

Data Availability Statement: The data presented in this study are available in this article.

Acknowledgments: Our special thanks to the D.I. Mendeleev University of Chemical Technology of Russia (Department of Innovative Materials and Corrosion Protection).

Conflicts of Interest: The authors declare no conflict of interest.

\section{References}

1. Kerstnera, E.K.; Kunsta, S.R.; Beltramia, L.V.R.; Vega, M.R.O. Anticorrosive performance of commercial nanoceramic coatings on AISI 1010 steel. Mater. Res. 2014, 17, 1497-1506. [CrossRef]

2. Yi, A.; Li, W.; Du, J.; Mu, S. Preparation and properties of chrome-free colored Ti/Zr based conversion coating on aluminum alloy. Appl. Surf. Sci. 2012, 258, 5960-5964. [CrossRef]

3. Cui, C.; Wang, D.; Li, X.; Qu, F.; Xu, T. A room temperature pre-treatment process: $\mathrm{Ce}^{3+}$ doted $\mathrm{ZrO}_{2}$. Nanofilm coated on the cold-rolled plate surface. Adv. Mater. Res. 2012, 347, 147-152.

4. Zhai, Y.; Zhao, Z.; Frankel, G.S.; Zimmerman, J.; Bryden, T.; Fristad, W. Surface Pretreatment Based on Dilute Hexafluorozirconic Acid. In Proceedings of the 2007 Three-Service Corrosion Conference, Denver, CO, USA, 3-6 December 2007; pp. 1-16.

5. Adhikaria, S.; Unocica, K.A.; Zhaia, Y.; Frankela, G.S.; Zimmermanb, J.; Fristad, W. Hexafluorozirconic acid based surface pretreatments: Characterization and performance assessment. Electrochim. Acta. 2011, 56, 1912-1924. [CrossRef]

6. Nela, J.T.; Plessisa, W.D.; Nhlabathia, T.N.; Pretoriusa, C.J.; Jansena, A.A.; Crouse, P.L. Reaction kinetics of the microwave enhanced digestion of zircon with ammonium acid fluoride. J. Fluor. Chem. 2011, 132, 258-262. [CrossRef]

7. Zhurinov, M.Z.; Statsyuk, V.N.; Fogel, L.A.; Bold, A.; Abrashov, A.A.; Kostiuk, A. Determination of the optimal deposition conditions oxide-zirconium coating on steel base. Rasayan J. Chem. 2019, 12, 1287-1293. [CrossRef]

8. Fedrizzi, L.; Rodriguez, F.J.; Rossi, S.; Deflorian, F.; Maggio, R.D. The use of electrochemical techniques to study the corrosion behaviour of organic coatings on steel pretreated with sol-gel zirconia films. Electrochim. Acta 2001, 46, 3715-3724. [CrossRef]

9. Dunham, B.; Chalk, D.D. Non-phosphate transition metal coatings. Clean. Pretreat. Surf. Prep. 2001, 1, $112-118$.

10. Abrashov, A.A.; Grigoryan, N.S.; Vagramyan, T.A.; Meshalkin, V.P.; Kotel'nikova, A.V.; Gribanova, A.A. Protective adhesive zirconium oxide coatings. Prot. Met. Phys. Chem. Surf. 2016, 52, 1170-1174. [CrossRef]

11. Mohammadloo, H.E.; Sarabi, A.A. Titanium composite conversion coating formation on CRS in the presence of Mo and Ni ions: Electrochemical and microstructure characterizations. Appl. Surf. Sci. 2016, 387, 252-259. [CrossRef]

12. Shcram, T.; Goeminne, G.; Terryn, H.; Vanhools, W. Anticorrosive coating based on zirconium. Inst. Met. Finish. 1995, 73, 91-97.

13. Mohammadloo, H.E.; Sarabi, A.A.; Alvani, A.A.S.; Sameie, H.; Salimi, R. Nano-ceramic hexafluorozirconic acid based conversion thin film: Surface characterization and electrochemical study. Surf. Coat. Technol. 2012, 206, 4132-4139. [CrossRef]

14. Milosev, I.; Frankel, G.S. Review-Conversion coatings based on zirconium and/or titanium. J. Electrochem. Soc. 2018, 165, 127-144. [CrossRef]

15. Guan, Y.; Liu, J.; Yan, C. Novel Ti/Zr based non-chromium chemical conversion coating for the corrosion protection of electrogalvanized steel. Int. J. Electrochem. Sci. 2011, 6, 4853-4867.

16. Statsyuk, V.N.; Bold, A.; Zhurinov, M.Z.; Fogel, L.A.; Sassykova, L.R.; Vagramyan, T.A.; Abrashov, A.A. Using cyclic voltammetry to determine the protective ability of phosphate coatings. Funct. Mater. 2020, 27, 605-610. 
17. ASTM B117-11. Standard Practice for Operating Salt Spray (Fog) Apparatus. ASTM International: West Conshohocken, PA, USA, 2011.

18. Laha, P.; Schram, T.; Terry, H. Use of spectroscopic ellipsometry to study Zr/Ti film son Al. Surf. Interface Anal. 2002, 34, 677-680. [CrossRef]

19. State Standard (SS) 9.302-88. ESZKS. Metallic and Nonmetallic Coatings. Methods of Accelerated Corrosion Tests.

20. Abrashov, A.; Grigoryan, N.; Vagramyan, T.; Asnis, N. On the mechanism of formation of conversion titanium-containing coatings. Coatings 2020, 10, 328. [CrossRef] 